Jurnal Teknologi, bil. 26, Jun 1997 hlm. 13-22

(c) Universiti Teknologi Malaysia

\title{
PENENTUAN TABURAN TITISAN CUMENE DALAM TURUS PENGEKSTRAKAN CAKERA BERPUTAR DENGAN KAEDAH SIMULASI MONTE CARLO
}

\author{
JAMALLUDIN TALIB \\ Jabatan Matematik \\ Fakulti Sains \\ Universiti Teknologi Malaysia \\ 80990 Johor Bahru, Johor \\ Malaysia
}

\begin{abstract}
Abstrak. Pengekstrakan cecair-cecair dengan menggunakan turus pengekstrakan cakera berputar melibatkan salah satu dari cecair diserakkan dalam bentuk titisan di dalam cecair yang satu lagi. Taburan yang terbentuk akibat dari putaran cakera yang terdapat dalam turus tersebut menghasilkan titisan anak yang berbagai-bagai saiz. Taburan saiz bagi titisan anak tersebut akan ditentukan dengan kaedah simulasi Monte Carlo.
\end{abstract}

\section{PENGENALAN}

Dalam kajian yang dilakukan oleh Rod[9], Korchinsky dan Cruz-Pinto[5] dalam turus pengekstrakan cecair-cecair, menunjukkan bahawa maklumat berkenaan dengan taburan saiz titisan dalam turus tersebut diperlukan bagi merekabentuk atau mentafsir perjalanan turus tersebut. Saiz titisan dalam turus pengekstrakan susah hendak diukur apa lagi jika bilangannya begitu banyak. Kebanyakan kajian menentukan taburan ini adalah hasil kajian pepecahan titisan demi titisan dan dikaji oleh Cabasud et al [3], Bahmanyar [2], Jares dan Prochazka [7] dan Eid et al.[6]. Dalam makalah ini penulis akan meramalkan taburan saiz titisan dengan menggunakan kaedah simulasi Monte Carlo. Maklumat asas yang diperlukan bagi tujuan tersebut diperolehi dari ujikaji makmal Bahmanyar[2], Bahmanyar dan Slater [1] dan dari model pecahan Talib[15] dan model saiz [14]. Maklumat yang dimaksudkan akan diterangkan dalam bahagian 3. Urutan perbincangan penulis akan dimulakan dengan pengekstrakan cecair dan alat turus pengekstrakan cakera berputar. Ini diikuti dengan menjelaskan model-model yang berkaitan yang akan digunakan dalam kaedah simulasi Monic Carlo. Seterusnya penulis akan mengutarakan gabungan model bagi tujuan simulasi dan akhir sekali merumus hasil yang diperolehi.

\section{LATAR BELAKANG - PENGEKSTRAKAN CECAIR-CECAIR}

\subsection{Pengekstrakan Cecair-Cecair.}

Pengekstrakan cecair-cecair, adalah suatu proses pemisahan komponen A dalam cecair B dengan menggunakan satu cecair lain $\mathrm{C}$ yang disebut solven (pelarut). Pengasingan komponen A dalam B ke C, kebanyakannya adalah disebabkan oleh perbezaan kepekatan A dalam B dan A dalam C. Cecair B yang mengandungi A dinamakan suapan dan Cecair C yang mengandungi A dinamakan rafinat. Sifat cecair B dan C adalah tak boleh campur atau boleh campur separa di antara satu sama lain. 


\subsection{Turus Pengekstrakan Cecair-Cecair}

Bagi mempercepatkan pengasingan komponen A dari B ke C, salah satu dari cecair yang digunakan diserakkan(dispersed) dalam bentuk titisan ke dalam cecair yang satu lagi, yang juga disebut media. Terdapat berbagai-bagai jenis turus pengekstrakan dan yang paling banyak digunakan adalah yang dikenali sebagai turus pengekstrakan penyentuhan cakera berputar, dengan singkatan turus RDC. Satu susunan bagi turus pengekstrakan cakera berputar adalah diberikan dalam Rajah 1. Turus ini mula dibina oleh kumpulan Belanda dan Amsterdam pada tahun 1946, dengan ukuran diameter 1m dan ketinggian mencapai $4.5 \mathrm{~m}$. Cecair yang mempunyai ketumpatan yang tinggi dimasukkan di bahagian atas turus dan yang mempunyai ketumpatan rendah dimasukkan di bahagian bawahnya. Pergerakan cecair adalah bertentangan arah dan ini disebabkan perbezaan ketumpatan cecair tersebut. Bagi cecair yang hendak diserakkan ianya dimasukkan melalui satu distributor - yang mengeluarkan cecair dalam bentuk titisan, bagi cecair yang mempunyai ketumpatan rendah, titisan ini bergerak ke atas turus tersebut dan dipecahkan lagi oleh cakera berputar yang terletak di sepanjang turus tersebut. Cincin pegun yang terletak di antara cakera berputar juga memainkan peranan dalam proses pengekstrakan.

\subsection{Pecahan titisan cumene dalam air - tanpa peralihan jisim}

Kajian Bahmanyar[2] dan Bahmanyar dan Slater [1] dalam turus berukuran diameter $152 \mathrm{~mm}$ dan mempunyai dua puluh tiga tahap, beroperasi dengan kadar putaran cakera sebanyak 4.2 pusingan sesaat memperolehi maklumat berkenaan kebarangkalian pecahan titisan $\mathrm{p}$ dan persamaan taburan $\phi(x, y)$ yang digunakan bagi menentukan saiz titisan anak. Maklumat asas ini dibincangkan dalam bahagian seterusnya.

\subsubsection{Kebarangkalian pecahan titisan}

Bagi menentukan kebarangkalian pecahnya titisan, pemerhatian terhadap pergerakan titisan cumene yang bergerak menegak dalam media air dilakukan. Nisbah bilangan titisan yang berpecah apabila terkena cakera berputar dengan keseluruhan bilangan titisan didapatkan. Hasil dari kajian ini suatu persamaan kebarangkalian pecahnya suatu titisan dapat dikaitkan dengan nombor Weber, $\mathrm{We}_{m}$ yang memperihalkan nisbah tenaga kinetik kepada tenaga permukaan titisan - nisbah daya pemecahan titisan kepada daya mengelakkan dari berpecahnya titisan.

Kebarangkalian pecahan diberikan oleh

$$
p=\frac{0.01 \mathrm{We}_{m}^{11}}{1+0.01 \mathrm{We}_{m}^{11}}
$$

dengan nombor Weber $\mathrm{We}_{m}$ ialah

$$
\mathrm{We}_{m}=\rho_{c} d D_{R}^{2}\left(N^{2}-N_{C R}^{2}\right) / \gamma
$$

yang mana ketumpatan media adalah $\rho_{c}$, saiz titisan $d$, diameter cakera berputar $D_{R}$, putaran cakera $N$, putaran yang mula menghasilkan pecahan $N_{C R}$ dan ketegangan diantara permukaan dua cecair $\gamma$.

\subsubsection{Taburan Saiz Titisan Anak}

Dalam kajian yang dilakukan oleh Bahmanyar[2] dan Bahmanyar dan Slater[1]. persamaan taburan saiz bagi titisan dapat diwakili oleh

$$
\phi(x, y)=(x-1)(1-y)^{x-2}
$$


dengan $x$ adalah bilangan titisan anak dan $y$ adalah ukuran tak berdimensi bagi isipadu titisan, yang diberikan oleh $y=\left(d_{D} / d_{i}\right)^{3}$ dengan $d_{D}$ adalah saiz diameter bagi titisan anak dan $d_{i}$ adalah saiz diameter titisan ibu.

Kesemua maklumat dari perbincangan dalam bahagian 2.3.1 dan 2.3.2 akan digunakan sama ada secara langsung atau sebaliknya dalam pembentukan model pecahan titisan, model penentuan saiz dan model simulasi taburan dengan kaedah Monte Carlo.

\section{PEMBENTUKAN MODEL}

Hasil dari kajian Bahmanyar[2], saya akan mengutarakan satu model untuk mendapatkan taburan saiz titisan di sepanjang turus yang dipertimbangkan. Untuk tujuan tersebut, tiaptiap tahap turus RDC akan dimodelkan sebagai mengandungi beberapa ruang yang akan menampung sepuluh kumpulan titisan yang mempunyai saiz yang berbeza. Cara menentukan kumpulan saiz titisan dibincangkan dalam bahagian 3.1. Di samping itu juga taburan saiz yang diberikan oleh persamaan (2.3) akan diubahsuai supaya ianya boleh digunakan untuk mencari saiz-saiz tititisan yang pecah akibat terlanggar cakera berputar, ini diceritakan dalam bahagian 3.2 manakala sumber data mentah bagi pecahan dan bilangan titisan akan diambil dari kajian Bahmanyar[2]. Ini adalah seperti yang terkandung dalam bahagian 3.3 .

\subsection{Model Saiz Titisan Di Dalam Suatu Kumpulan}

Saiz titisan ibu mula diperolehi dari bahagian penyerak - distributor, jika diameter titisan ibu ini ialah $d_{o}$, maka kumpulan saiz titisan boleh dijana dengan saiz diameter ini. Kelas bagi kumpulan ini diperolehi seperti yang ditunjukkan oleh Talib[15] seperti berikut.

Jika bilangan kelas atau kumpulan yang ini dibentuk adalah $N_{c l}$, maka saiz bagi kelas $j, c_{j}$ adalah diameter titisan yang berukuran dari $d_{E, j}$ hingga $d_{E, j+1}$, yang mana $c_{j}=$ $d_{E, j+1}-d_{E, j}$ dan bagi $j=1, \ldots, N_{c l}$

$$
d_{E, j}=\frac{d_{0}}{N_{c l}} \times(j-1), \quad j=1, \ldots, N_{c l} .
$$

Jika diperhatikan saiz kelas adalah tidak bergantung kepada $j$, malahan kepada bilangan kelas dan saiz titisan ibu.

Hasil kajian Mugele and Evans [8], penggunaan purata diameter adalah lebih berkesan bagi menentukan perpecahan titisan jika dibandingkan dengan menggunakan keseluruhan taburan siaz titisan dan dengan anggapan bahawa titisan yang terhasil akibat pecahan titisan ibu adalah seragam dan disebabkan oleh pegiraan kecekapan peralihan jisim suatu titisan bergantung kepada isipadu titisan itu sendiri maka purata diameter bagi titisan dalam satu kelas akan didapatkan dengan membuat kiraan purata terhadap isipadu titisan dalam kelas tersebut. Bagi menentukan model yang diushakan oleh Talib[15] akan digunakan, model ini beranggapan bahawa jika dalam kelas $j$, titisan mempunyai purata isipadu $\bar{V}_{j}$ dan purata diameter $d_{a v, j}$, maka

$$
\bar{V}_{j}=\frac{4}{3} \pi\left(\frac{d_{a v, j}}{2}\right)^{3}
$$

tetapi purata isipadu $\bar{V}_{j}$ boleh juga ditulis sebagai

$$
\bar{V}_{j}=\frac{1}{3} \pi \int_{r_{j}}^{r_{j+1}} r^{3} d r /\left(r_{j+1}-r_{j}\right)
$$


dengan $r_{j+1}=\frac{d_{E, j+1}}{2}$ dan $r_{j}=\frac{d_{E, j}}{2}$.

Ini seterusnya menghasilkan

$$
\bar{V}_{j}=\frac{1}{3} \pi\left[\left(\frac{d_{E, j+1}}{2}\right)^{4}-\left(\frac{d_{E, j}}{2}\right)^{4}\right] /\left(r_{j+1}-r_{j}\right) .
$$

Dengan menyamakan persamaan (3.2) dan (3.4), purata diameter bagi titisan dalam ku mpulan $j$ adalah

$$
d_{a v, j}^{3}=\frac{1}{4}\left\{\left(d_{E, j+1}+d_{E, j}\right)\left(d_{E, j+1}^{2}+d_{E, j}^{2}\right)\right\}
$$

\subsection{Model Bilangan Anak}

Bilangan titisan anak terhasil bukan sahaja bergantung kepada sifat sistem atau sifat geometrik turus yang digunakan, tetapi bergantung juga kepada saiz titisan ibu. Bagi sistem dan turus yang sama bilangan titisan anak yang terhasil hanya bergantung kepada saiz titisan ibu. Talib[15] telah memperolehi persamaan yang mengaitkan saiz titisan ibu dan bilangan anak yang terhasil, dan persamaan-persamaan ini adalah ciri penting bagi menjana bilangan anak terhasil. Persamaan bagi pecahan titisan kepada dua, tiga, empat dan lima titisan anak, masing-masing diberikan oleh

$$
\begin{array}{ll}
f_{2}(d)=4.73 d^{-1.15}, & 3.9 \leq d \leq 7.05 \\
f_{3}(d)=2.9 \times d^{-2} d^{1.14}, & 4.2 \leq d \leq 7.05 \\
f_{4}(d)=3.0 \times d^{-4} d^{3.28}, & 5.5 \leq d \leq 7.05 \\
f_{5}(d)=1-\sum_{m=2}^{4} f_{m}(d), & 6.0 \leq d \leq 7.05,
\end{array}
$$

dengan $d$ adalah saiz diameter titisan ibu.

\subsection{Model Saiz Titisan Anak}

Pengubahsuaian ungkapan (2.3) adalah perlu untuk tujuan simulasi. Model yang diutarakan oleh Talib[15] dapat menentukan saiz titisan anak dengan menggunakan nombor rawak. Hasil dari kajian tersebut, bagi $k$ titisan anak yang terhasil saiz(isipadu) titisan anak tersebut dinyatakan seperti yang berikut.

Bagi titisan anak pertama, saiznya adalah

$$
v_{i}=V S_{l}
$$

Nombor rawak $S_{l}=r$ diperolehi dari taburan seragam [0,1]. Saiz $v_{i}$ bagi titisan anak $i, \quad i=2,3, \ldots, k-1$ adalah

$$
v_{i}=\left(V-\sum_{j=l}^{i-1} v_{j}\right) S_{l}
$$

dan saiz titisan anak ke $k$, ialah

$$
v_{k}=V-\sum_{j=1}^{i-1} v_{j}
$$

dimana $S_{i}=1-\left(1-r_{i}\right)^{1 / x-1}$, dengan $x=2, \ldots, k$ titisan anak dan $r_{i}$ adalah nombor rawak yang dihasilkan dari taburan seragam $[0,1]$. 


\section{SIMULASI BERASASKAN KAEDAH MONTE CARLO}

Secara ringkasnya kaedah Monte Carlo membolehkan sebarang proses yang bergantung kepada unsur rawak disimulasikan. Dalam urus pengekstrakan cakera berputar, pergerakan titisan serta pecahannya kepada titisan yang lebih kecil adalah secara rawak maka dengan menggunakan konsep kerawakan ini kaedah Monte Carlo bagi pergerakan serta pecahan titisan dalam turus dibina.

Untuk tujuan simulasi, data-data yang digunakan adalah seperti yang diberikan dalam Lampiran I. Bagi mensimulasikan proses pecahan ini, kita mulakan dengan titisan yang diketahui saiznya. Apabila titisan ini melalui cakera putar pertama ia akan ditentukan sama ada ianya pecah atau tidak, dengan membandingkan nilai pecahan yang didapati dari persamaan (2.1) dengan nombor rawak yang dijana dari taburan seragam. Jika titisan tadi tidak pecah ianya akan terus dimasukkan dalam kumpulan yang sama tetapi berada dalam tahap kedua, sebaliknya jika titisan tersebut pecah, proses penentuan bilangan titisan anak yang diperolehi akan ditentukan dengan model bilangan anak dan seterusnya menentukan saiz titisan dengan model saiz titisan masing-masing seperti yang diterangkan dalam bahagian 3.3 dan 3.4, dan seterusnya dimasukkan ke dalam kumpulan yang sesuai pada tahap kedua. Proses penentuan pecahan, bilangan anak dan saiz titisan anak dan kemasukan ke kumpulan yang sesuai pada tahap yang lebih tinggi diringkaskan dengan singkatan PBSK, ditunjukkan dalam atur cara dalam Lampiran II. Simulasi bagi menentukan taburan adalah dianggap lengkap, dan bagi setiap titisan yang masuk akan melalui proses setiap tahap sehingga ke tahap tettinggi sekali dengan proses PBSK tersebut. Untuk tujuan simulasi tersebut, aturcara program dalam fortran telah ditulis dan dijalankan dengan menggunakan komputer peribadi 486 dengan kelajuan $33 \mathrm{mhz}$. Ianya mengambil masa yang selama lebih kurang 8 jam untuk menjana taburan bagi turus RDC dengan 23 tahap.

\section{ULASAN DAN KESIMPULAN}

Data hasil dari simulasi ini diberikan dalam lampiran III. Taburan titisan yang terhasil dari gabungan model saiz titisan (bahagian 3.1), model bilangan anak (bahagian 3.2) dan model saiz titisan anak (bahagian 3.3) diberikan dalam Lampiran IV.

Pada Lampiran IV, didapati bahawa graf taburan titisan membentuk ke suatu taburan normal apabila titisan meningkat pada tahap tinggi. Ini ditunjukkan dalam graf taburan pada tahap 14 dan 22 pada Lampiran IV. Pada tahap 22 pula, taburan titisan dengan kaedah Monte Carlo dibandingkan dengan taburan kaedah jangkaan EV (Talib[13]) dan juga model Mugele-Evans[8]. Graf menunjukkan taburan yang terhasil ini adalah setanding dengan taburan yang dihasilkan oleh Mugele-Evans[8]. Walaupun kaedah simulasi Monte Carlo mengambil masa selama 8 jam untuk menjana taburan titisan yang lengkap, taburan ini lebih baik dari taburan EV(Talib[13]).

Satu kelemahan kaedah simulasi Monte Carlo ialah masa yang digunakan terlalu lama untuk mendapatkan sesuatu taburan titisan. Antara penyebabnya ialah penentuan pecahan titisan yang bergantung kepada sistem cecair yang digunakan. Setiap kali sesuatu sistem digunakan banyak faktor berkaitan dengan taburan saiz dan pecahan titisan perlu diubah dalam proses simulasi. Walaupun banyak masa diperlukan dan terlalu banyak faktor yang perlu dimasukkan ke dalam kaedah Monte Carlo, kaedah ini masih yang terbaik kerana proses yang melibatkan pergerakan dan perpecahan titisan cecair dalam cecair adalah suatu proses stokastik. 


\section{RUJUKAN}

[1] H. Bahmanyar \& M. J. Slater, Chemical Engineering Technology 14 (1991), 79-89.

[2] H. Bahmnayar, Ph.D Thesis-Rotating Disc Contactor \& Mass Transfer, University Of Bradford, 1989.

[3] M. Cabasud, C. Gourdan \& G. Casamatta, Chemical Engineering Journal 44 (1990), 27-41.

[4] D.K. Chang-Kakoti, W-Y. Fei, J.C. Godfrey \& M.J. Slater, J. separ. Proc. Technol. .6 (1985), 40-48.

[5] J. J. C. Cruz-Pinto \& W. J. Korchinsky, Chemical Engineering Sci. 35 (1980), 2213.

[6] K. Eid, C. Gourdon, G. Cassamatta \& G. Muratet, Pros. ISEC 86, Munich 3 (1986), 353-360.

[7] J. Jares, \& J. Prochazka, Chem. Eng. Sc. 42 no. 2 (1987), 283-292.

[8] R. A. Mugele \& H. D. Evans, Ind. Eng. Chem. 43 no. 6 (1951), 1317-1324.

[9] V. Rod \& T. Misek, Trans. Ichem. Eng 60 (1982), 48-53.

[10] F.Schreider, Statistical Testing, Academic Press, 1966.

[11] M. J. Slater, A review of current advanced procedures for liquid-liquid extraction columns and present problems, I.Chem.E. Symposium Series no. 118 (1980).

[12] L. Steiner, Chem. Eng. Sci. 41 no. 8 (1986), 1979-1986.

[13] J. Talib, Mathematical Modelling Of A Rotating Disc Contactor Column, Ph.D Thesis, University Of Bradford, 1994.

[14] J. Talib, Perkembangan Model Matematik dalam Pembinaan Alat Turus Pengekstrakan Cakera Berputar $(R D C)$, Seminar Sains Dan Industri, UTM (27-12-94) (1994).

[15] J. Talib, Model-Model Dalam Menentukan Bilangan Titisan Anak Yang Terhasil Dari Pecahan Titisan Ibu, Akan di terbitkan (1995).

\section{Sifat Geometrik Turus Pengekstrakan Cakera Berputar}

Bilangan tahap

Ketinggian di antara tahap $(\mathrm{m})$

Diameter rotor discs $(\mathrm{m})$

Diameter turus $(\mathrm{m})$

Diameter cincin pemegun $(\mathrm{m})$

Halaju cakera (pusingan/s)
: 23

: 0.076

: 0.1015

: 0.1520

: 0.1110

: 4.2

\section{Sifat Fizikal Sistem (cumene/air/asid isobutarik)}

fasa media - asid isobutarik dalam air

fasa serakan(titisan) - asid isobutarik dalam cumene

Kelikatan fasa media $(\mathrm{kg} / \mathrm{ms})$

Kelikatan fasa serakan $(\mathrm{kg} / \mathrm{ms})$

Ketumpatan fasa media $\left(\mathrm{kg} / \mathrm{m}^{3}\right)$

$: 0.100 \mathrm{E}-2$

$: 0.710 \mathrm{E}-3$

Ketumpatan fasa serakan $\left(\mathrm{kg} / \mathrm{m}^{3}\right)$

$: 0.100 \mathrm{E}+4$

$: 0.862 \mathrm{E}+3$

Kemeresapan molekul bagi fasa media $\left(\mathrm{m}^{2} / \mathrm{s}\right)$

$: 0.850 \mathrm{E}-9$

Kemerasapan molekul bagi fasa $\operatorname{serakan}\left(\mathrm{m}^{2} / \mathrm{s}\right)$

$: 0.118 \mathrm{E}-8$ 


\section{Lampiran I}

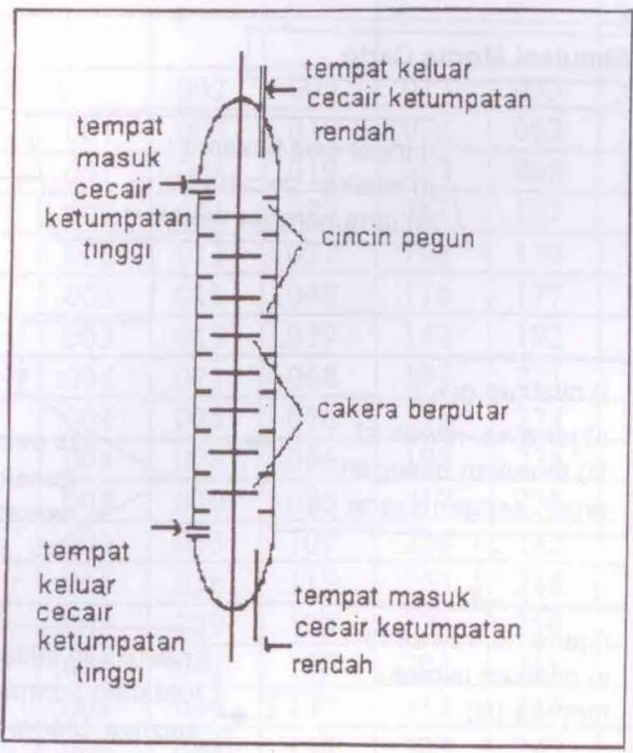

Rajah 1 Turus RDC

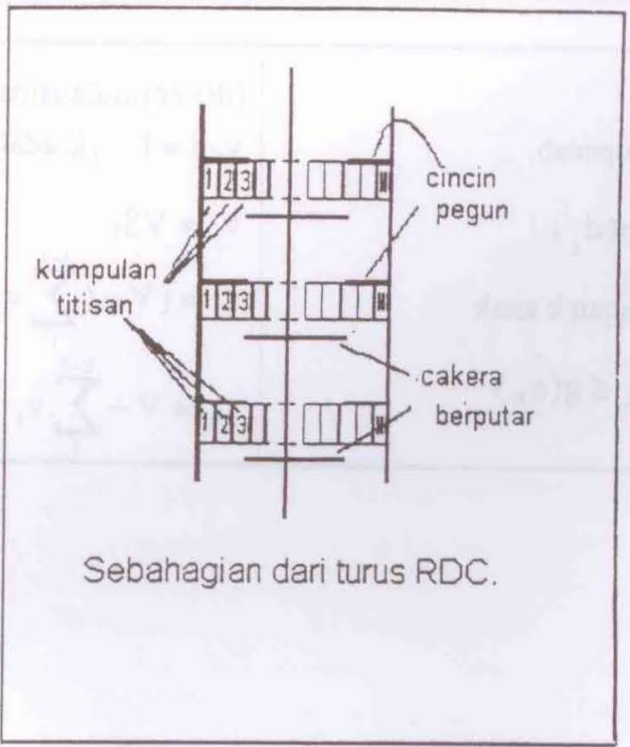

Rajah 2 Model kumpulan 
Lampiran II

Rajah 3 Carta alir PBSK

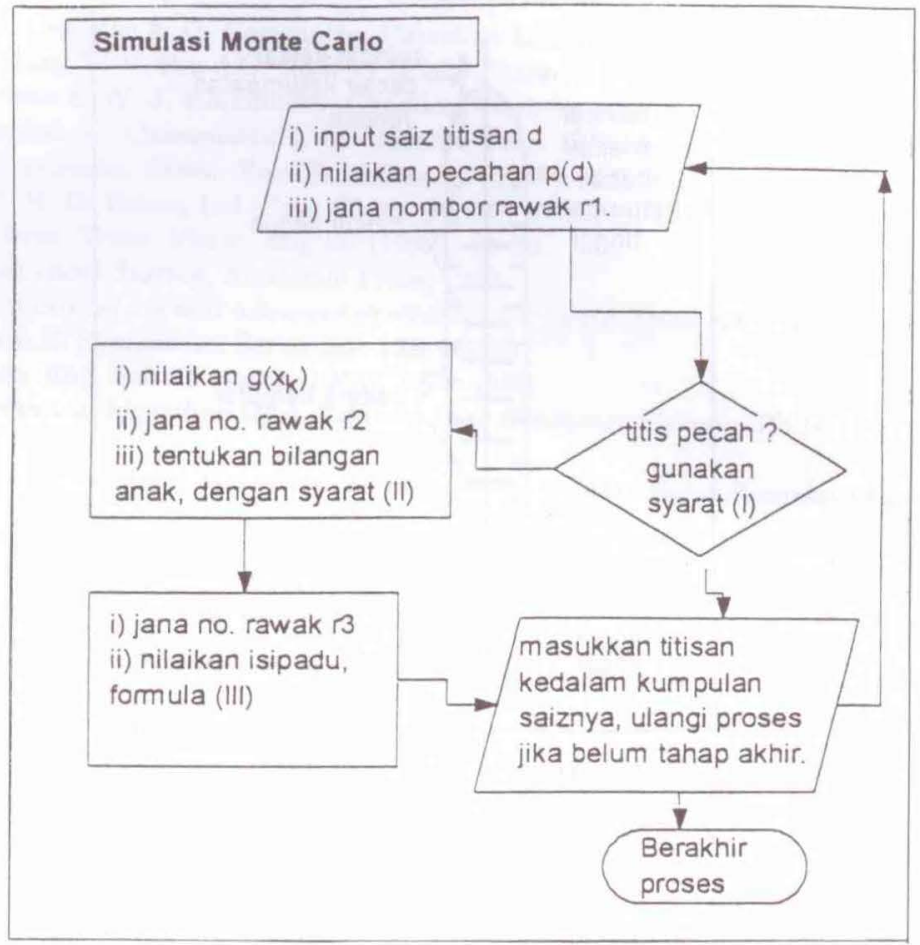

(I). Syarat titisan pecah

$$
0 \leq \mathrm{r}_{1} \leq \mathrm{p}\left(\mathrm{d}_{\mathrm{i}}\right)
$$

(II). Syarat bilangan $\mathrm{k}$ anak

$$
\mathrm{g}\left(\mathrm{x}_{\mathrm{k}-1}\right) \leq \mathrm{r}_{2} \leq \mathrm{g}\left(\mathrm{x}_{\mathrm{k}}\right)
$$

(III) Formula isipadu saiz titisan unak $v_{i}, i=1, \ldots, k$ adalah

$\mathrm{v}_{1}=\mathrm{VS}_{1}$

$v_{i}=\left(V-\left(\sum_{i}^{i-1} v_{j}\right) S_{i}, i=2, \ldots, k-1\right.$

$\mathrm{v}_{\mathrm{k}}=\mathrm{V}-\sum_{1}^{\mathrm{k}-1} \mathrm{v}_{\mathrm{j}}$ 


\section{Lampiran III}

Jadual 1 Nisbah isipadu titisan bagi setiap kumpulan bagi 22 tahap turus RDC

\begin{tabular}{|l|l|l|l|l|l|l|l|l|l|l|}
\hline$\frac{\text { kump }}{\text { tahap }}$ & 1 & 2 & 3 & 4 & 5 & 6 & 7 & 8 & 9 & 10 \\
\hline 1 & 0 & 0 & 0 & .002 & .005 & .013 & .033 & .066 & .106 & .775 \\
\hline 2 & 0 & 0 & .001 & .005 & .010 & .031 & .062 & .103 & .162 & .626 \\
\hline 3 & 0 & 0 & .001 & .008 & .019 & .057 & .068 & .121 & .193 & .503 \\
\hline 4 & 0 & 0 & .002 & .011 & .027 & .081 & .127 & .165 & .220 & .368 \\
\hline 5 & 0 & 0 & .002 & .013 & .037 & .102 & .150 & .204 & .210 & .281 \\
\hline 6 & 0 & 0 & .003 & .016 & .048 & .116 & .177 & .206 & .203 & .231 \\
\hline 7 & 0 & 0 & .003 & .019 & .059 & .142 & .192 & .216 & .199 & .169 \\
\hline 8 & 0 & 0 & .004 & .021 & .068 & .159 & .221 & .210 & .187 & .129 \\
\hline 9 & 0 & 0 & .004 & .025 & .076 & .178 & .233 & .219 & .169 & .097 \\
\hline 10 & 0 & 0 & .005 & .028 & .086 & .198 & .238 & .223 & .148 & .073 \\
\hline 11 & 0 & .001 & .005 & .030 & .096 & .217 & .238 & .221 & .135 & .056 \\
\hline 12 & 0 & .001 & .006 & .033 & .109 & .236 & .242 & .215 & .112 & .047 \\
\hline 13 & 0 & .001 & .006 & .036 & .117 & .253 & .248 & .203 & .093 & .043 \\
\hline 14 & 0 & .001 & .007 & .039 & .128 & .274 & .250 & .191 & .075 & .034 \\
\hline 15 & 0 & .001 & .008 & .043 & .137 & .294 & .245 & .183 & .065 & .023 \\
\hline 16 & 0 & .001 & .008 & .046 & .147 & .313 & .244 & .170 & .052 & .019 \\
\hline 17 & 0 & .001 & .009 & .048 & .154 & .323 & .243 & .166 & .045 & .011 \\
\hline 18 & 0 & .001 & .009 & .052 & .165 & .337 & .235 & .161 & .033 & .006 \\
\hline 19 & 0 & .001 & .010 & .055 & .176 & .351 & .229 & .150 & .023 & .006 \\
\hline 20 & 0 & .001 & .010 & .058 & .186 & .362 & .226 & .137 & .015 & .004 \\
\hline 21 & 0 & .001 & .011 & .061 & .194 & .366 & .229 & .122 & .012 & .004 \\
\hline 22 & 0 & .001 & .011 & .064 & .204 & .375 & .221 & .109 & .011 & .004 \\
\hline
\end{tabular}


Lampiran IV Graf menunjukkan taburan titisan di beberapa tahap pengekstrakan cakera berputar, RDC.
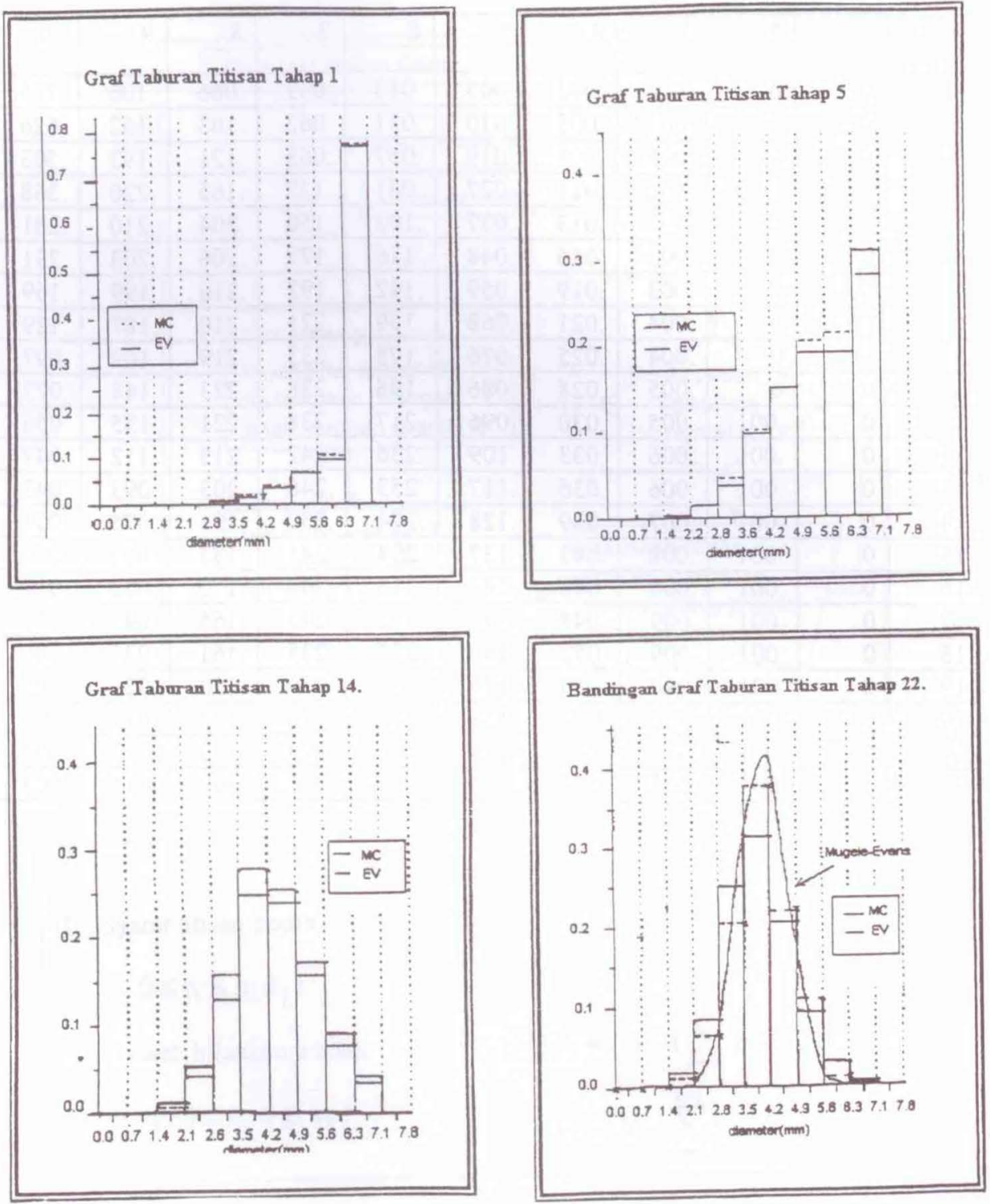